\title{
Papers
}

\section{Effect of comorbidities and postoperative complications on mortality after hip fracture in elderly people: prospective observational cohort study}

\author{
JJ W Roche, R T Wenn, O Sahota, C G Moran
}

\begin{abstract}
Objectives To evaluate postoperative medical complications and the association between these complications and mortality at 30 days and one year after surgery for hip fracture and to examine the association between preoperative comorbidity and the risk of postoperative complications and mortality.

Design Prospective observational cohort study.

Setting University teaching hospital.

Participants 2448 consecutive patients admitted with an acute hip fracture over a four year period. We excluded 358 patients: all those aged $<60$; those with periprosthetic fractures, pathological fractures, and fractures treated without surgery; and patients who died before surgery.

Interventions Routine care for hip fractures.

Main outcome measures Postoperative complications and mortality at 30 days and one year.

Results Mortality was $9.6 \%$ at 30 days and $33 \%$ at one year. The most common postoperative complications were chest infection $(9 \%)$ and heart failure $(5 \%)$. In patients who developed postoperative heart failure mortality was $65 \%$ at 30 days (hazard ratio $16.1,95 \%$ confidence interval 12.2 to 21.3 ). Of these patients, $92 \%$ were dead by one year $(11.3,9.1$ to 14.0$)$. In patients who developed a postoperative chest infection mortality at 30 days was $43 \%$ (8.5, 6.6 to 11.1$)$. Significant preoperative variables for increased mortality at 30 days included the presence of three or more comorbidities $(2.5,1.6$ to 3.9$)$, respiratory disease (1.8, 1.3 to 2.5$)$, and malignancy (1.5, 1.01 to 2.3$)$.

Conclusions In elderly people with hip fracture, the presence of three or more comorbidities is the strongest preoperative risk factor. Chest infection and heart failure are the most common postoperative complications and lead to increased mortality. These groups offer a clear target for specialist medical assessment.
\end{abstract}

\section{Introduction}

Hip fractures related to osteoporosis constitute a major clinical and financial burden to the NHS. In 2002-3, there were 78554 admissions to NHS hospitals in England for fractured neck of femur, $96 \%$ of these were in people aged $\geq 65 .{ }^{1}$ Bed occupancy for hip fracture was in excess of 1.5 million days, which represents $20 \%$ of total orthopaedic bed stays and in women over 45 accounts for a higher proportion of occupancy of hospital beds than many other common disorders. ${ }^{2}$ Excess mortality is $20 \%$ in the first year and is higher in older men. ${ }^{34}$
The high mortality, particularly in the first three months, is probably due to the combination of trauma, major surgery in elderly people with concurrent medical problems, ${ }^{3}$ and a low physiological reserve. Identifying which patients are at greatest risk of developing complications and which types of complications are life threatening has never been examined in a large prospective study.

We investigated how demographic factors and important medical conditions influence postoperative complications and mortality. Other important factors, such as delay to surgery, ${ }^{5}$ type of treatment, and length of stay, were beyond the scope of this study.

We evaluated postoperative medical complications, the association between these complications and mortality at 30 days and one year, and the association between preoperative comorbidity, the risk of postoperative complications, and mortality in elderly patients presenting with an acute hip fracture.

\section{Patients and methods}

We prospectively evaluated all patients admitted to the university hospital in Nottingham with a hip fracture from 8 May 1999 to 7 May 2003. Follow-up ended on 7 June 2003. This is the only hospital providing a trauma service for Nottingham and its surrounding area; it has a catchment population of 675000 . Independent audit staff collected data on these patients by using a detailed proforma based on the standardised audit of hip fractures in Europe. ${ }^{6}$ Data included demographics, type of fracture, preoperative comorbidities, operative treatment, and complications. Integration with the database of the Office for National Statistics ensured accurate mortality data for every patient. Comorbidities on admission were identified from the patient's history, medication, and medical records (table 1).

The anaesthetist routinely assessed all patients and referred those deemed to be too unwell for immediate surgery to the resident medical registrar for treatment recommendations. All patients who had surgery were included in the study.

We diagnosed complications clinically or after investigations and recorded them prospectively until the time of hospital discharge (table 1). For the purpose of this analysis we excluded patients with simultaneous bilateral fractures $(n=6)$, periprosthetic fractures $(n=25)$, and pathological fractures $(n=63)$, and patients $<60$ years $(\mathrm{n}=165)$, those dying before a decision to treat was made $(n=20)$, and those treated without an operation $(\mathrm{n}=79: 42$ undisplaced fractures, four patients who presented more than 10 days after the injury, 22 who were severely unwell, and 11 who refused surgery). 
Table 1 Comorbidity and postoperative complications in 2448 elderly people with hip fracture

\begin{tabular}{lc}
\hline Comorbidity & No $(\%)$ \\
\hline Cardiovascular disease & $597(24)$ \\
\hline Stroke & $322(13)$ \\
\hline Respiratory disease & $343(14)$ \\
\hline Renal disease & $66(3)$ \\
\hline Diabetes mellitus & $232(9)$ \\
\hline Rheumatoid disease & $84(3)$ \\
\hline Parkinson's disease & $97(4)$ \\
\hline Malignancy & $186(8)$ \\
\hline Paget's disease & $13(1)$ \\
\hline Current smokers & $240(10)$ \\
\hline Enteral steroids & $52(2)$ \\
\hline No of comorbidities: & $861(35)$ \\
\hline 1 & $414(17)$ \\
\hline 2 & $162(7)$ \\
\hline$\geq 3$ & $215(9)$ \\
\hline Postoperative complication & $119(5)$ \\
\hline Chest infection & $42(2)$ \\
\hline Cardiac failure & $27(1)$ \\
\hline DVT/PE & $98(4)$ \\
\hline Deep infection & $20(1)$ \\
\hline Urinary tract infection & $25(1)$ \\
\hline Gastrointestinal haemorrhage & $35(1)$ \\
\hline Myocardial infarction & $331(14)$ \\
\hline Stroke & $133(5)$ \\
\hline No of complications: & $34(1)$ \\
\hline 1 & \\
\hline 2 & \\
\hline$\geq 3$ & \\
\hline DVT/PE & \\
\hline 1
\end{tabular}

DVT/PE=deep vein thrombosis/pulmonary embolus.

\section{Statistical methods}

Our measured outcomes were postoperative complications and mortality at 30 days and one year. We used univariate Cox regression analysis to evaluate the crude effect of comorbidities and complications on mortality. Multivariate Cox regression analysis allowed adjustment for age, sex, and the confounding variables shown in table 1 . Multivariate logistic regression determined the association between postoperative complications and comorbidities on admission. We have presented the hazard ratios and odds ratios generated at the final step of analysis. We used multivariate Cox and logistic regression analyses to ensure results for variables such as age and sex were generated even if they were not significant. The significance level for all statistical tests was set at $5 \%(\mathrm{P}<0.05)$. Data were coded and stored in Microsoft Excel 2000 and analysed with the SPSS statistical program (version 12.0.1)

\section{Results}

\section{Demographics}

Over the four year period 2806 patients were admitted with a hip fracture. We excluded 358, leaving 2448 patients within the study. The mean age was 82 years (range 60-103 years), and $80 \%$ (1955) were women (table 2).

The median score of the mini-mental test was 7 out of 10 (range 0-10); 1485 patients (61\%) had good cognitive function (score 7-10), and 580 (24\%) had severe cognitive impairment (score 0-3). Patients were admitted from their own homes (61\%), warden-aided accommodation (10\%), residential homes $(15 \%)$, nursing homes (13\%), and elsewhere (2\%). Of the fractures, $57 \%$ were intracapsular and 43\% were extracapsular. The median
Table 2 Age and sex distribution (\% in age group)

\begin{tabular}{lccc} 
Age (years) & Total $(\%)$ & Women $(\%)$ & Men $(\%)$ \\
\hline $60-69$ & $196(8)$ & $118(64)$ & $66(36)$ \\
\hline $70-79$ & $661(27)$ & $510(76)$ & $160(24)$ \\
\hline $80-89$ & $1126(46)$ & $910(81)$ & $208(19)$ \\
\hline$\geq 90$ & $465(19)$ & $417(88)$ & $59(12)$ \\
\hline Total & 2448 & $1955(80)$ & $493(20)$ \\
\hline
\end{tabular}

length of stay was 12 days on a trauma ward (interquartile range 8-17 days) and 18 days (11-30 days) when we included time on rehabilitation wards.

\section{Comorbidities}

Forty one per cent (1011) had no comorbidity; 35\% had one, $17 \%$ had two, and $7 \%$ had three or more comorbidities. Table 1 lists the comorbidities recorded and their incidence. The most common were cardiovascular disease (24\%), chronic obstructive airways disease (14\%), and cerebrovascular disease (13\%).

\section{Postoperative complications}

Twenty percent of patients (498/2448) had a postoperative complication. The complication rate was $14 \%$ (147/1011) for patients with no comorbidity on admission. Table 1 shows the incidence of postoperative complications. The most common complications were chest infection (9\%, 215/2448; diagnosed clinically in the presence of fever, clinical findings with or without radiographic changes consistent with bronchopneumonia); heart failure $(5 \%, 119 / 2448$; diagnosed clinically with or without radiographic changes consistent with acute left ventricular failure); and urinary tract infection (4\%, 98/2448; diagnosed positive results on urine culture). There were 35 cerebrovascular events (diagnosed with computerised tomography) and 25 myocardial infarctions (diagnosed by changes on electrocardiogram together with a rise in troponin I concentration).

\section{Mortality}

Mortality was $9.6 \%$ at 30 days $(\mathrm{n}=231)$ and $33 \%$ at one year $(\mathrm{n}=747)$. Mortality at 30 days was $8.2 \%(\mathrm{n}=158)$ in women and $15 \%(\mathrm{n}=73)$ in men, a significant difference (log rank test 20.91, $\mathrm{P}<0.01)$.

Table 3 shows unadjusted hazard ratios for individual complications and comorbidities. Table 4 shows the results of the multivariate Cox regression analysis. In patients with postoperative heart failure the mortality was $65 \%$ at 30 days $(n=77 / 119)$ (hazard ratio $8.0,95 \%$ confidence interval 5.5 to 11.6). At one year the mortality was $92 \%(n=109 / 119)(5.0,3.9$ to 6.5$)$. In patients who developed a postoperative chest infection the mortality was $43 \%(\mathrm{n}=92 / 215)(3.0,2.1$ to 4.2$)$ at 30 days and $71 \%$ $(\mathrm{n}=153 / 215)(2.4,1.9$ to 3.0$)$ at one year.

Forty two patients $(1.7 \%)$ developed deep vein thrombosis (diagnosed by Doppler ultrasonography or venogram, or both) or pulmonary embolus (diagnosed by ventilation/perfusion (V/Q) scan or CT angiography) despite receiving prophylactic low molecular weight heparin. In these patients the hazard ratio was 4.5 (2.7 to 7.6$)$ for death at 30 days.

\section{Preoperative risk factors for mortality}

After adjustment for age and sex, patients with three or more comorbidities had a hazard ratio for death at 30 days of 2.5 (1.6 to 3.9 ). The figure shows the unadjusted mortality curve over the first 30 postoperative days. Table 5 shows the results of the multivariate Cox regression analysis. Significant factors for increased mortality at 30 days include number of comorbidities present on admission-patients with three or more comorbidities being at increased risk compared with those with none (hazard ratio 2.5, 
Table 3 Univariate Cox regression analysis of all variables for mortality at 30 days and one year: final step. Figures are hazard ratios (95\% confidence intervals)

\begin{tabular}{|c|c|c|}
\hline & 30 day mortality & 1 year mortality \\
\hline Male sex & $1.9(1.4 \text { to } 2.5)^{\text {** }}$ & $1.8(1.5 \text { to } 2.1)^{\star *}$ \\
\hline \multicolumn{3}{|l|}{ Age (years)t: } \\
\hline $60-69$ & 1 & \\
\hline $70-79$ & $1.2(0.6$ to 2.4$)$ & $1.4(0.9$ to 2.0$)$ \\
\hline $80-89$ & 1.9 (0.97 to 3.6) & 2.1 (1.5 to 3.0$)$ \\
\hline$\geq 90$ & 2.7 (1.4 to 5.2) & 3.0 (2.1 to 4.3$)$ \\
\hline \multicolumn{3}{|l|}{ Comorbidities } \\
\hline Cardiovascular disease & 1.2 (0.9 to 1.6$)$ & $1.4(1.2 \text { to } 1.6)^{\star *}$ \\
\hline Stroke & 1.4 (1.0 to 1.9) & $1.2(0.9$ to 1.4$)$ \\
\hline Respiratory disease & $1.9(1.4 \text { to } 2.5)^{\star *}$ & $1.6(1.3 \text { to } 1.9)^{\star *}$ \\
\hline Renal disease & $2.8(1.6 \text { to } 4.6)^{\star *}$ & $2.7(1.8 \text { to } 3.4)^{\star *}$ \\
\hline Diabetes & $1.2(0.8$ to 1.8$)$ & $1.4(1.2 \text { to } 1.8)^{*}$ \\
\hline Rheumatoid disease & $1.0(0.5$ to 2.0$)$ & 0.8 (0.5 to 1.3$)$ \\
\hline Parkinson's disease & $1.6(0.9$ to 2.7$)$ & $1.4(1.0 \text { to } 1.9)^{\star}$ \\
\hline Malignancy & $1.7(1.1 \text { to } 2.5)^{\star}$ & $1.6(1.3 \text { to } 2.0)^{\star *}$ \\
\hline Paget's disease & 0.8 (0.1 to 5.7) & $2.1(1.0 \text { to } 4.5)^{\star}$ \\
\hline Current smokers & $0.5(0.2$ to 0.8$)$ & $0.9(0.7$ to 1.1$)$ \\
\hline Enteral steroids & 1.8 (0.9 to 3.6$)$ & 2.0 (1.4 to 3.0$)$ \\
\hline \multicolumn{3}{|l|}{ No of comorbiditiest: } \\
\hline 0 & 1 & 1 \\
\hline 1 & 1.3 (1.1 to 1.5$)$ & 1.2 (1.0 to 1.5$)$ \\
\hline 2 & 1.7 (1.5 to 2.1$)$ & 1.7 (1.4 to 2.0$)$ \\
\hline$\geq 3$ & 2.4 (1.9 to 3.1$)$ & 2.4 (1.9 to 3.1$)$ \\
\hline \multicolumn{3}{|c|}{ Postoperative complications } \\
\hline Chest infection & $8.5(6.6 \text { to } 11.1)^{\star \star}$ & $5.0(4.2 \text { to } 6.0)^{\star *}$ \\
\hline Cardiac failure & $16.1(12.2 \text { to } 21.3)^{\star \star *}$ & $11.3(9.1 \text { to } 14.0)^{\star * *}$ \\
\hline DVT/PE & $5.1(3.1 \text { to } 8.6)^{\star *}$ & 2.6 (1.7 to 3.8$)$ \\
\hline Deep infection & 0.1 (0 to 10.7) & $2.1(1.3 \text { to } 3.4)^{*}$ \\
\hline Urinary tract infection & 0.7 (0.3 to 1.5) & 1.1 (0.8 to 1.5) \\
\hline Gastrointestinal bleed & $3.7(1.7 \text { to } 8.4)^{*}$ & $3.0(1.7 \text { to } 5.2)^{\star *}$ \\
\hline Myocardial infarction & $4.6(2.4 \text { to } 9.0)^{\star *}$ & $3.5(2.2 \text { to } 5.7)^{\star \star}$ \\
\hline Stroke & $3.1(1.6 \text { to } 6.0)^{\star}$ & $3.5(2.3 \text { to } 5.2)^{\star \star}$ \\
\hline \multicolumn{3}{|l|}{ No of complicationst: } \\
\hline 0 & 1 & 1 \\
\hline 1 & 5.6 (4.1 to 7.6$)$ & 2.9 (2.2 to 3.2 ) \\
\hline 2 & 13.0 (9.3 to 18.0$)$ & 6.5 (5.2 to 8.1$)$ \\
\hline$\geq 3$ & 8.8 (4.7 to 16.5$)$ & 5.8 (3.9 to 8.5) \\
\hline
\end{tabular}

DVT/PE=deep vein thrombosis/pulmonary embolus.

${ }^{\star} \mathrm{P}<0.05 ;{ }^{*} \mathrm{*}<0.01$.

$\dagger P<0.01$ for 30 day and one year mortality.

1.6 to 3.9$)$, male sex $(1.2,1.5$ to 2.6$)$, respiratory disease $(1.8,1.3$ to 2.5$)$, and renal disease $(2.0,1.2$ to 3.5$)$. Increasing age was also a significant factor.

\section{Preoperative risk factors for postoperative complications}

Chest infection-Respiratory disease (odds ratio 2.7, 1.9 to 3.8), male sex (2.0, 1.5 to 2.8$)$, enteral steroids (2.5, 1.2 to 5.2$)$, and greater age were all important risk factors for developing a chest infection after surgery for hip fracture (table 6). Interestingly, in our patients smoking was not a significant risk factor $(\mathrm{P}=0.098$, table 6). Compared with those with no comorbidity, patients with an increasing number of comorbidities had greater risk of postoperative chest infection (odds ratios were 1.7 (1.2 to 2.5) for one comorbidity, 2.2 (1.5 to 3.3) for two, and 5.3 (3.3 to 8.5) for three or more).

Cardiac failure - Age $\geq 90$ years compared with younger (4.1, 1.5 to 10.9$)$, male sex $(1.8,1.2$ to 2.8$)$, and a history of cardiovascular disease (2.3, 1.6 to 3.4 ) were all significant risks for developing postoperative heart failure (table 6). Patients with two or three or more comorbidities on admission had an increased risk of developing postoperative heart failure compared with those with no comorbidity $(2.0,1.2$ to 3.5 , and $4.6,2.5$ to 8.3 ,
Table 4 Multivariate Cox regression analysis of all variables for 30 day and one year mortality. Figures are hazard ratios ( $95 \%$ confidence intervals)

\begin{tabular}{|c|c|c|}
\hline & 30 day mortality & 1 year mortality \\
\hline Male sex & $1.5(1.1 \text { to } 2.0)^{*}$ & $1.8(1.5 \text { to } 2.1)^{* *}$ \\
\hline \multicolumn{3}{|l|}{ Age (years) $\dagger:$} \\
\hline \multicolumn{3}{|l|}{ 60-69 } \\
\hline $70-79$ & 1.1 (0.5 to 2.1$)$ & 1.3 (0.9 to 2.0$)$ \\
\hline $80-89$ & 1.3 (0.7 to 2.6$)$ & 2.0 (1.4 to 2.8$)$ \\
\hline$\geq 90$ & 1.5 (0.8 to 3.0$)$ & 2.8 (1.9 to 4.1$)$ \\
\hline \multicolumn{3}{|l|}{ Comorbidities } \\
\hline Cardiovascular disease & 0.7 (0.5 to 0.9$)$ & $1.0(0.8$ to 1.2$)$ \\
\hline Respiratory disease & $1.6(1.1 \text { to } 2.2)^{*}$ & $1.4(1.1 \text { to } 1.7)^{\star}$ \\
\hline Stroke & 0.97 (0.7 to 1.4) & 0.9 (0.8 to 1.2$)$ \\
\hline Renal disease & $1.8(1.01 \text { to } 3.2)^{\star}$ & $1.6(1.1 \text { to } 2.3)^{*}$ \\
\hline Diabetes & 0.97 (0.6 to 1.5$)$ & $1.3(1.0 \text { to } 1.6)^{*}$ \\
\hline Parkinson's disease & $1.1(0.6$ to 2.0$)$ & $1.1(0.8$ to 1.6$)$ \\
\hline Rheumatoid disease & 0.97 (0.5 to 2.0) & $0.9(0.6$ to 1.4$)$ \\
\hline Paget's disease & 0.9 (0.1 to 6.4$)$ & $1.9(0.9 \text { to } 4.1)^{*}$ \\
\hline Enteral steroids & $1.5(0.7$ to 3.0$)$ & $1.7(1.1 \text { to } 2.6)^{*}$ \\
\hline Malignancy & $1.6(1.1 \text { to } 2.5)^{\star}$ & $1.6(1.2 \text { to } 2.0)^{\star \star}$ \\
\hline Current smokers & $0.3(0.2 \text { to } 0.6)^{*}$ & 0.8 (0.6 to 1.1$)$ \\
\hline \multicolumn{3}{|c|}{ Postoperative complications } \\
\hline Chest infection & $3.0(2.1 \text { to } 4.2)^{\star \star}$ & $2.4(1.9 \text { to } 3.0)^{\star \star}$ \\
\hline Cardiac failure & $8.0(5.5 \text { to } 11.6)^{\star \star}$ & $5.0(3.9 \text { to } 6.5)^{* *}$ \\
\hline Urinary tract infection & $0.6(0.3$ to 1.4$)$ & 0.9 (0.6 to 1.3) \\
\hline DVT/PE & $4.5(2.7 \text { to } 7.6)^{\star \star *}$ & $2.1(1.4 \text { to } 3.1)^{\star}$ \\
\hline Gastrointestinal bleed & $3.3(1.4 \text { to } 7.7)^{\star}$ & $2.5(1.4 \text { to } 4.5)^{*}$ \\
\hline Myocardial infarction & $3.2(1.6 \text { to } 6.5)^{*}$ & $2.4(1.4 \text { to } 4.0)^{*}$ \\
\hline Stroke & $1.6(0.8 \text { to } 3.3)^{\star \star}$ & $2.4(1.6 \text { to } 3.7)^{\star \star}$ \\
\hline Deep wound infection & $0(0$ to $\infty)$ & $1.1(0.7$ to 1.9$)$ \\
\hline
\end{tabular}

DVT/PE=deep vein thrombosis/pulmonary embolus.

${ }^{*} \mathrm{P}<0.05 ;{ }^{*} \mathrm{P}<0.01$.

$\dagger P<0.01$ for 30 day and one year mortality.

respectively). Even in a study with 2448 patients, the numbers with a postoperative myocardial infarction, clinical pulmonary embolus, or deep vein thrombosis were insufficient to identify any specific risk factors. Those patients with previous stroke were at increased risk of a second stroke in the postoperative period $(4.7,2.3$ to 9.5$)$.

\section{Discussion}

Heart failure and chest infection are thought to be major postoperative complications in elderly patients undergoing surgery for hip fracture, ${ }^{78}$ and our large prospective study confirms this. The demographics of our study population were

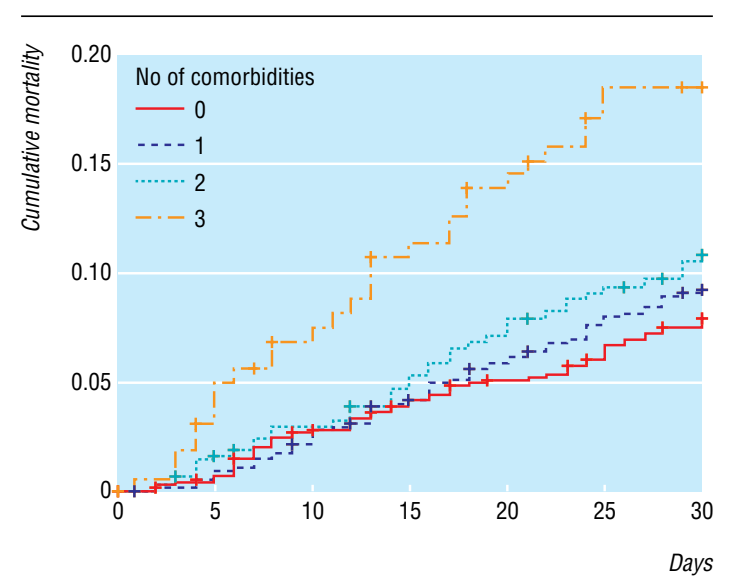

Survival analysis based on number of preoperative comorbidities 
Table 5 Multivariate Cox regression analysis of effect of all preoperative variables on 30 day mortality. Figures are hazard ratios $(95 \%$ confidence intervals)

\begin{tabular}{lc}
\hline Male sex & Hazard ratio \\
\hline Age (years) ${ }^{\star *}:$ & $2.0(1.5 \text { to } 2.6)^{\star *}$ \\
\hline $60-69$ & 1 \\
\hline $70-79$ & $1.2(0.6$ to 2.4$)$ \\
\hline $80-89$ & $2.0(1.0$ to 3.7$)$ \\
\hline$\geq 90$ & $3.0(1.5$ to 5.9$)$ \\
\hline Comorbidities & \\
\hline Cardiovascular disease & $1.01(0.8$ to 1.4$)$ \\
\hline Respiratory disease & $1.8(1.3 \text { to } 2.5)^{\star *}$ \\
\hline Stroke & $1.4(1.0$ to 2.0$)$ \\
\hline Rheumatoid disease & $1.1(0.6$ to 2.3$)$ \\
\hline Malignancy & $1.5(1.0 \text { to } 2.3)^{\star}$ \\
\hline Renal disease & $2.0(1.2 \text { to } 3.5)^{\star}$ \\
\hline Diabetes & $1.1(0.7$ to 1.7$)$ \\
\hline Parkinson's disease & $1.4(0.8$ to 2.4$)$ \\
\hline Paget's disease & $0.6(0.1$ to 4.5$)$ \\
\hline Enteral steroids & $1.8(0.9$ to 3.7$)$ \\
\hline Current smokers & $0.5(0.2 \text { to } 0.8)^{\star}$ \\
\hline
\end{tabular}

${ }^{*} \mathrm{P}<0.05 ;{ }^{*} \mathrm{P}<0.01$.

similar to previously reported UK studies. ${ }^{4}$ The 30 day mortality is comparable with that of the Oxford NHS health region from 1984-98 and is also typical of other units within the UK, ${ }^{9}{ }^{10}$ Europe, and the US. ${ }^{3711}$ Our most striking result was the high mortality for patients who developed acute heart failure or a chest infection after surgery for hip fracture. In the 30 days after surgery, 13\% (334) of our patients developed one of these complications yet they accounted for 73\% (169) of the deaths.

Patients with more comorbidities on admission had a greater risk of postoperative complications and increased mortality. This is consistent with results of previous smaller retrospective studies. ${ }^{8}{ }^{12}$ Cardiovascular disease and chronic lung disease predispose patients to the most common and serious postoperative complications. These patients may be a target group for specialist preoperative medical assessment.

Table 6 Multivariate logistic regression analysis of effect of all preoperative variables on incidence of postoperative chest infection and cardiac failure. Figures are odds ratios ( $95 \%$ confidence intervals)

\begin{tabular}{lcc} 
& \multicolumn{1}{c}{ Chest infection } & Cardiac failure \\
\hline Male sex & $2.0(1.5 \text { to } 2.8)^{\star *}$ & $1.8(1.2 \text { to } 2.8)^{\star}$ \\
\hline Age (years)†: & 1 & \\
\hline $60-69$ & $1.5(0.7$ to 3.0$)$ & $1.2(0.4$ to 3.2$)$ \\
\hline $70-79$ & $2.1(1.1$ to 4.3$)$ & $2.2(0.8$ to 5.6$)$ \\
\hline $80-89$ & $4.0(1.9$ to 8.3$)$ & $4.1(1.5$ to 10.9$)$ \\
\hline$\geq 90$ & & \\
\hline Comorbidities & $1.3(0.9$ to 1.7$)$ & $2.3(1.6 \text { to } 3.4)^{\star *}$ \\
\hline Cardiovascular disease & $2.7(1.9 \text { to } 3.8)^{\star *}$ & $1.3(0.8$ to 2.2$)$ \\
\hline Respiratory disease & $1.5(1.0 \text { to } 2.2)^{\star}$ & $1.6(1.0$ to 2.6$)$ \\
\hline Stroke & $0.8(0.3$ to 2.0$)$ & $2.0(0.9$ to 4.6$)$ \\
\hline Rheumatoid disease & $1.1(0.6$ to 1.8$)$ & $0.8(0.4$ to 1.8$)$ \\
\hline Malignancy & $2.3(1.2 \text { to } 4.3)^{\star}$ & $1.6(0.7$ to 3.6$)$ \\
\hline Renal disease & $1.3(0.8$ to 2.0$)$ & $1.7(1.0$ to 2.9$)$ \\
\hline Diabetes & $1.9(1.0 \text { to } 3.6)^{*}$ & $1.2(0.5$ to 3.1$)$ \\
\hline Parkinson's disease & $1.8(0.4$ to 8.4$)$ & $0(0$ to $\infty)$ \\
\hline Paget's disease & $2.5(1.2 \text { to } 5.2)^{\star}$ & $1.5(0.5$ to 4.4$)$ \\
\hline Enteral steroids & $1.5(0.9$ to 2.3$)$ & $1.2(0.6$ to 2.4$)$ \\
\hline Current smokers &
\end{tabular}

$\dagger P<0.01$ for chest infection and cardiac failure.

\section{Management of high risk patients}

To reduce mortality, attention must focus on optimising health status preoperatively, preventing postoperative complications, and, when these complications develop, providing optimal specialist medical care. No study has specifically examined high risk patients who may have most to gain from more specialised medical care. The difference in outcome between patients who have access to joint orthopaedic and geriatric care and those who do not has been investigated. ${ }^{13}{ }^{14}$ These studies mainly evaluated interventions related to rehabilitation rather than acute medical assessment and, unsurprisingly, have not shown a significant difference in early mortality. Despite this, as far back as 1989 the Royal College of Physicians recommended medical assessment of patients with hip fracture to reduce their operative risk, ${ }^{15}$ and this has been reinforced in several subsequent publications. ${ }^{16}{ }^{17}$ Specialist medical assessment and management of elderly patients with hip fracture before and after surgery, however, remains uncommon in the UK. The resident medical registrar assessed a number of our patients after anaesthetic assessment, and they subsequently underwent surgery. The number assessed was small and most of the patients who died postoperatively had no formal specialist medical assessment before or after surgery.

Further studies would identify optimal management for these patients, but experience suggests that they may benefit from specialist senior medical input both before and after surgery. A retrospective study of over 8000 elderly patients with hip fracture found that perioperative transfusion had no influence on mortality in patients with haemoglobin concentrations $>80 \mathrm{~g} / 1,{ }^{18}$ but smaller studies have shown that transfusion at higher haemoglobin concentrations for patients with known cardiac disease may be beneficial. ${ }^{19}{ }^{20}$ Persistent hypoxia may be present in all patients with hip fracture from the time of admission until up to five days postoperatively, ${ }^{21}$ and episodes of myocardial ischaemia occur in postoperative patients with known ischaemic heart disease. ${ }^{22}$ Therefore measures such as higher triggers for transfusion and monitoring oxygen saturation and arterial blood gases before and after surgery may help reduce complications.

Invasive physiological monitoring with oesophageal Doppler ultrasonography or pulmonary artery catheters in the perioperative period may be of benefit. ${ }^{23}$ In other surgical specialities, outcome is improved in high risk patients undergoing major surgery in whom fluid and inotrope therapy is monitored with pulmonary artery catheters. ${ }^{24}$ This has not been extrapolated to orthopaedic surgery. These invasive techniques, however, may be helpful in optimising cardiac output and reducing postoperative cardiac failure in the vulnerable patients we have identified.

\section{Strengths and weaknesses}

It was not possible to have diagnostic criteria driven by protocol, and treatment for each comorbidity and more accurate premorbid data would have been useful-for example, echocardiography to assess the degree of heart failure or lung function tests to define the severity of lung disease. The study was observational and did not look at different systems of care for these patients. However, we did have complete data on a large consecutive series of patients with $100 \%$ follow-up for mortality statistics. This study reflects everyday clinical practice in the UK. National audits based on hospital episode statistics, such as those produced by Imperial College and Dr Foster (www.drfoster.co.uk), provide only crude mortality data. In contrast, we also provided information on comorbidities, complications, and mortality. 


\section{What is already known on this topic?}

Mortality is high after surgery for hip fracture in elderly patients

Postoperative complications are associated with a poor outcome

\section{What this study adds}

Patients with multiple comorbidities, especially respiratory disease and malignancy, before surgery for hip fracture are at higher risk of mortality

Postoperative complications, such as chest infection and heart failure, are also associated with increased mortality

\section{Conclusions}

We have shown a $9 \%$ mortality at 30 days after hip fracture in elderly patients. A fifth of patients had a postoperative complication, the most common being chest infection and heart failure. Within 30 days of surgery $65 \%$ of patients with heart failure and $43 \%$ with postoperative chest infection died. Most patients (92\%) with heart failure died within a year of surgery. Age, male sex, and the presence of three or more comorbidities on admission all predicted a high risk of complications. Further studies are urgently required to evaluate different systems of medical care to establish whether these can reduce the incidence and severity of these complications and improve the standard of care for elderly patients with hip fracture.

We thank N Badhe, N D Downing, D M Hahn, M Hatton, B J Holdsworth, C J Howell, J B Hunter, P J James, A R J Manktelow, J A Oni, P J Radford, B E Scammell, E P Szypryt, and A M Taylor for allowing their patients to be included in this study. We also thank Christopher T White for his assistance with statistical analysis and Sarah Armstrong (University of Nottingham) for her supervision of the statistical analysis.

Contributors: JJWR carried out the literature search and wrote the manuscript. RTW collected the data, carried out statistical analyses, and reviewed the manuscript. OS was involved with writing the paper, interpreting data, and critical revision. CGM was responsible for conception and management of the study and audit design, edited the manuscript, and is guarantor.

Funding: None.

Competing interests: None declared.

Ethical approval: Not required.

1 Department of Health. Hospital episode statistics. www.hesonline.nhs.uk (accessed Oct 2005).

2 Royal College of Physicians. Osteoporosis. Clinical guidelines for prevention and treatment. London: Royal College of Physicians of London, 1999.
3 Kenzora JE, McCarthy RE, Lowell JD, Sledge CB. Hip fracture mortality. Relation to age, treatment, preoperative illness, time of surgery, and complications. Clin Orthop Relat Res 1984;186:45-56.

4 Keene GS, Parker MJ, Pryor GA. Mortality and morbidity after hip fractures. BMJ 1993;307:1248-50.

5 Moran CG, Wenn RT, Sikand M, Taylor AM. Early mortality after hip fracture: is delay before surgery important? J Bone Joint Surg Am 2005;87:483-9.

6 SAHFE. Standardized audit of hip fractures in Europe. Lund: Lund University Hospital, 1997. www.sahfe.ort.lu.se (accessed Oct 2005).

7 Eiskjaer S, Ostgard SE. Risk factors influencing mortality after bipolar hemiarthroplasty in the treatment of fracture of the femoral neck. Clin Orthop Relat Res plasty in the treating

8 Nettleman MD, Alsip J, Schrader M, Schulte M. Predictors of mortality after acute hip fracture. J Gen Intern Med 1996;11:765-7.

9 Todd CJ, Freeman CJ, Camilleri-Ferrante C, Palmer CR, Hyder A, Laxton CE, et al. Differences in mortality after fracture of hip: the east Anglian audit. BMJ 1995;310:904-8. 10 Roberts SE, Goldacre MJ. Time trends and demography of mortality after fractured neck of femur in an English population, 1968-98: database study. BMJ 2003;327:771-5.

11 Forsen L, Sogaard AJ, Meyer HE, Edna T, Kopjar B. Survival after hip fracture: shortand long-term excess mortality according to age and gender. Osteoporos Int 1999;10:73-8.

12 Dirksen A, Kjoller E. Cardiac predictors of death after non-cardiac surgery evaluated by intention to treat. $B M J 1988 ; 297: 1011-3$.

13 Hempsall VJ, Robertson DR, Campbell MJ, Briggs RS. Orthopaedic geriatric care-is it effective? A prospective population-based comparison of outcome in fractured neck of effective? A prospective population-based com
femur. J R Coll Physicians Lond 1990;24:47-50.

14 Khan R, Fernandez C, Kashifl F, Shedden R, Diggory P. Combined orthogeriatric care in the management of hip fractures: a prospective study. Ann $R$ Coll Surg Engl 2002;84:122-4.

15 Fractured neck of femur. Prevention and management. Summary and recommendations of a report of the Royal College of Physicians.J R Coll Physicians Lond 1989;23:812 .

16 Scottish Intercollegiate Guidelines Network. Prevention and management of hip fracture in older people. Edinburgh: Scottish Intercollegiate Guidelines Network, 2002.

17 British Orthopaedic Association. The care of fragility fracture patients. London: British Orthopaedic Association, 2003.

18 Carson JL, Duff A, Berlin JA, Lawrence VA, Poses RM, Huber EC, et al. Perioperative blood transfusion and postoperative mortality. JAMA 1998;279:199-205.

19 Nelson AH, Fleisher LA, Rosenbaum SH. Relationship between postoperative anemia and cardiac morbidity in high-risk vascular patients in the intensive care unit. Crit Care Med 1993;21:860-6.

20 Hogue CW Jr, Goodnough LT, Monk TG. Perioperative myocardial ischemic episodes are related to hematocrit level in patients undergoing radical prostatectomy. Transfusion 1998;38:924-31.

21 Dyson A, Henderson AM, Chamley D, Campbell ID. An assessment of postoperative oxygen therapy in patients with fractured neck of femur. Anaesth Intensive Care 1988; $16: 405-10$

22 Juelsgaard P, Sand NP, Felsby S, Dalsgaard J, Jakobsen KB, Brink O, et al. Perioperative myocardial ischaemia in patients undergoing surgery for fractured hip randomized to incremental spinal, single-dose spinal or general anaesthesia. Eur I Anaesthesiol incremental spi

23 Price JD, Sear JW, Venn RM. Perioperative fluid optimization following proximal femoral fracture. Cochrane Database Syst Rev 2005;(2):CD003004.

24 Boyd O, Grounds RM, Bennett ED. A randomized clinical trial of the effect of deliberate perioperative increase of oxygen delivery on mortality in high-risk surgical patients. JAMA 1993;270:2699-707.

(Accepted 16 September 2005)

doi $10.1136 /$ bmj. 38643.663843 .55

Department of Trauma and Orthopaedics, University Hospital Nottingham,

Nottingham, NG7 2UH

JJ W Roche clinical fellow

$\mathrm{R}$ T Wenn audit coordinator

C G Moran professor

Department of Care of the Elderly, University Hospital Nottingham, Nottingham O Sahota consultant physician

Correspondence to: C G Moran anne.hay@qmc.nhs.uk 